\title{
EDITORIAL
}

\section{LA U.D.C.A: UNA UNIVERSIDAD PARA TODOS}

\author{
Germán Anzola Montero \\ Rector
}

La U.D.C.A será un proyecto educativo, construido a partir de la participación activa de un grupo de pensamiento universitario, integrado por los miembros de su alta dirección: Asamblea de Fundadores y Consejo Directivo; directivos académicos y administrativos; docentes y estudiantes. Y son ellos, precisamente, quienes deben responder a la pregunta: cंcuál es la Universidad que se desea para el siglo XXI?, queriendo decir, que debemos avanzar en un proyecto orientado a contribuir con la transformación de la Educación Superior y articulado en torno a la docencia, a la investigación y a la proyección a la sociedad nacional e internacional, para que todas sus acciones conduzcan al desarrollo y a la innovación, requerida para mejorar la calidad de los bienes y los servicios en función de las necesidades, en particular, de la sociedad colombiana, así como la competitividad internacional del país. Para ello es necesario definir objetivos que conduzcan al logro de resultados directos y específicos en lo referente a su fortalecimiento institucional, su internacionalización y su verdadera integración a los problemas de orden nacional y regional.

Cuando hablamos de fortalecimiento hacemos referencia a la prioritaria necesidad de favorecer el impulso de sus capacidades académicas y administrativas y a la cualificación de todos sus procesos, para obtener mayores y mejores beneficios, conducentes a su desarrollo institucional.

Enfatizar en la internacionalización de la U.D.C.A es referirnos al fomento de las interacciones con redes universitarias, gestionar vínculos con otras universidades del contexto mundial, fortalecer la movilidad de todos los estamentos universitarios y estimular todo tipo de actividades de cooperación interinstitucional, para crear condiciones que conduzcan a ayudas y apoyos de carácter internacional.
Ser partícipes de todo tipo de acciones, que hoy en día se identifican como "espacios comunes de la educación superior", nos deben encauzar a ser actores activos en los procesos de integración nacional y regional.

A partir de estas consideraciones, resulta pertinente analizar cómo la U.D.C.A se debe integrar a la propuesta considerada por el Consejo Nacional de Rectores, del 18 y 19 de marzo de 2010 y que bajo el título "Hacia una nueva Dinámica Social de la Educación Superior", presentó la Asociación Colombiana de Universidades ASCUN. Este documento de políticas, previstas para el período 2010 - 2014, tuvo como referente los protocolos producidos en la Conferencia Regional de Educación Superior 2008 (CRES-Cartagena), los Foros Rectorales 2008 - 2009, los informes de las Mesas ASCUN - MEN de 2009 y el comunicado de la Segunda Conferencia Mundial sobre la Educación Superior, París 2009. ASCUN conformó un equipo de trabajo denominado GRUPO FOCAL, cuyo objetivo es reflexionar sobre estas referencias citadas y otros documentos acerca del tema y determinar una serie de principios para la formulación de las políticas públicas de educación superior, que la U.D.C.A las acoge como propias. Ellas son:

1. Responsabilidad social y misión de la educación superior:

Formar el talento humano idóneo, competente y ético.

Contribuir en la creación del conocimiento y al desarrollo de la ciencia y de la tecnología e innovación, para beneficio de la sociedad.

Formar ciudadanos en los valores y las competencias del servicio a la justicia, al compromiso social y a la creatividad. 


\section{Descentralización y desconcentración:}

Las cuales deben conducir a la pertinencia y a la desconcentración de la oferta educativa.

\section{Financiación de la Educación Superior:}

$>$ Recursos financieros para el ofrecimiento del bien público y del servicio público, tanto para las instituciones públicas como privadas. Para ello se requiere de una política inaplazable por parte del Estado colombiano.

\section{Respeto y ejercicio de la autonomía:}

$>$ El Estado propugnará por la defensa, la promoción y el impulso de la autonomía responsable de las instituciones de educación superior, muy en particular de las Universidades como tal.

Los principios formulados, conllevan a la propuesta específica de políticas públicas para la educación superior, que podemos expresar, a manera de síntesis, en los siguientes términos:

> Fortalecer el Vice Ministerio de Educación Superior, argumentando el lograr incrementar actividades relacionadas con un mayor apoyo al subsistema de ciencia y tecnología.

$>$ Reforzar las funciones de fomento a la educación superior, como constructivo complemento a las responsabilidades de inspección de vigilancia.

> Estimular, aún más, los procesos de acreditación de alta calidad.

$>$ Optimizar las estrategias para estimular las relaciones entre la educación media y la educación superior.

> Diferenciar clara y específicamente la diversificación y las responsabilidades en los diferentes tipos de instituciones, que conforman en la actualidad la educación superior (técnicas profesionales, tecnológicas, instituciones universitarias y universidades).

$>$ Fortalecimiento financiero de la educación superior.

> Transformar la docencia universitaria como factor en la calidad de la educación superior.

> Afianzar los procesos de internacionalización de la Universidad Colombiana.
Si los lectores de esta reseña del documento elaborado por ASCUN confronta lo expuesto y lo ejecutado en el vigente plan de desarrollo y en el que en la actualidad venimos perfilando podrán encontrar, claramente, cómo el compromiso de la U.D.C.A con el sistema de la educación superior colombiana ha sido constante e incondicional; todos los planteamientos de políticas públicas vienen siendo compartidas, a partir de nuestros proyectos particulares en ejecución. El compromiso para con el avance nacional y regional es evidente.

Comentario especial merece el capítulo relativo a nuestro compromiso con los docentes. A pesar de las limitaciones de orden financiero, propias de una universidad privada, desde hace diez años venimos ejecutando un programa de desarrollo profesoral, que ha permitido cualificar, de manera particular, las labores académicas, encomendadas a ellos. Similar comentario podríamos hacer frente a dos temas prioritarios en la agenda universitaria, del nivel nacional y mundial, como son los procesos de internacionalización y educación ambiental en lo superior y el uso de las nuevas tecnologías de la información y de la comunicación, al servicio de la formación académica y de la administración institucional.

A pesar de ser un hecho muy reciente, no puedo dejar pasar por alto la obtención de la certificación ISO9001 a los procedimientos administrativos y de admisiones de la U.D.C.A, por parte de ICONTEC, demostrando así el compromiso con la cultura de transparencia y de "Rendición de Cuentas", establecida en la Universidad.

Tampoco puedo sustraerme de hacer un comentario de nuestra planta física. La U.D.C.A es un medio educativo para lo superior; pedagógicamente, hemos definido un proyecto de educación superior dirigido a una formación integral de los estudiantes, siendo para ello justo y necesario pensar en la adecuada atención a los espacios y volúmenes, donde nuestros alumnos han de transcurrir prolongadas jornadas del complejo compromiso intelectual, cultural, social y administrativo. Estas deben ser gratas, confortables y agradables, a partir de diseños arquitectónicos funcionales en el quehacer universitario; no deben ser sólo áreas en función de las tradicionales actividades de trabajo teórico y práctico, hoy requerimos de espacios, denominados por muchos "inteligentes", donde sean viables para el uso de las nuevas tecnologías al servicio de la educación 
superior (salas de cómputo, estudios de radio y de televisión, con sistemas de excelente conectividad). En este sentido, la U.D.C.A viene desarrollando estudios, para que su campus universitario, del norte de Bogotá, cumpla con estas exigencias y, complementariamente, una sede en el centro de la ciudad, con el propósito de atender óptimamente los procesos educativos a nivel de pregrado, de posgrado y de educación para el trabajo y el desarrollo humano, que requieren una sede en la zona central de Bogotá.
Es así, como la Universidad de Ciencias Aplicadas y Ambientales U.D.C.A desea brindar a la sociedad colombiana un servicio educativo a la altura de las exigencias del siglo XXI, formando excelentes profesionales, pero igualmente hombres y mujeres en el más grande, en el más comprensivo y en el más humano sentido de la palabra; hombres y mujeres que solo busquen la verdad y que sepan que no podrán encontrar la razón como universitarios responsables, sino en un trabajo con plena autonomía. 